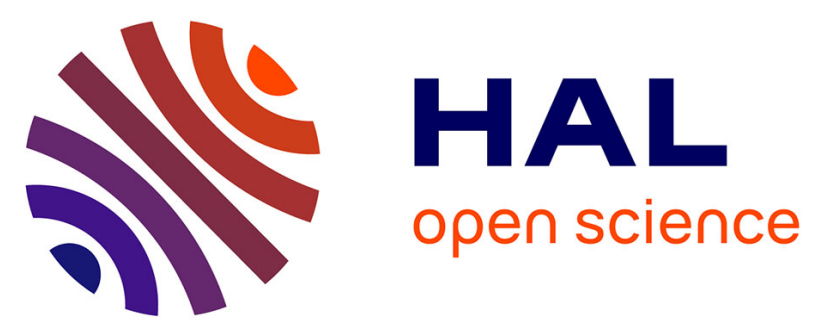

\title{
Development of a Hybrid Analytical Model for a Fast Computation of Magnetic Losses and Optimization of Coaxial Magnetic Gears
}

Melaine Desvaux, Stéphane Sire, Sami Hlioui, H. Ben Ahmed, B. Multon

\section{- To cite this version:}

Melaine Desvaux, Stéphane Sire, Sami Hlioui, H. Ben Ahmed, B. Multon. Development of a Hybrid Analytical Model for a Fast Computation of Magnetic Losses and Optimization of Coaxial Magnetic Gears. IEEE Transactions on Energy Conversion, 2019, 34 (1), pp.25-35. 10.1109/TEC.2018.2858859 . hal-01853745

\author{
HAL Id: hal-01853745 \\ https://hal.science/hal-01853745
}

Submitted on 13 Mar 2019

HAL is a multi-disciplinary open access archive for the deposit and dissemination of scientific research documents, whether they are published or not. The documents may come from teaching and research institutions in France or abroad, or from public or private research centers.
L'archive ouverte pluridisciplinaire HAL, est destinée au dépôt et à la diffusion de documents scientifiques de niveau recherche, publiés ou non, émanant des établissements d'enseignement et de recherche français ou étrangers, des laboratoires publics ou privés. 


\title{
Development of a Hybrid Analytical Model for a Fast Computation of Magnetic Losses and Optimization of Coaxial Magnetic Gears
}

\author{
M. Desvaux, S. Sire, S. Hlioui and H. Ben Ahmed, B. Multon, Member, IEEE
}

\begin{abstract}
This article focuses on a 2D analytical model for a fast computation of magnetic losses due to eddy currents in the permanent magnets as well as iron losses in the ferromagnetic parts within coaxial magnetic gears. The magnetic field distribution is computed in yokes and permanent magnets by solving both Maxwell's equations, whereas for pole pieces the magnetic field is computed by coupling the previous analytical model with a reluctance network model. Both the eddy current losses and iron losses are determined from this hybrid analytical model. The iron loss model takes into account the temporal and spatial variations of flux density. The eddy current loss model takes into account the magnet splitting. Results of this magnetostatic eddy current loss model are then compared to the results obtained with a $2 \mathrm{D}$ magnetodynamic finite element model. A verification of validity limits is also proposed. The final function of this analytical model is to ensure integration into a set of models in the aim of a global mechatronic optimization of magnetic gears, for their insertion into a multi-megawatt wind turbines. A preliminary bi-objective, mass-efficiency optimization protocol is subsequently proposed along with an analysis of the computation time reduction via the presented models.
\end{abstract}

Index Terms-- Fast computation, eddy current loss, permanent magnet, hybrid analytical model, permeance network, iron loss, magnetic gear, optimization.

\section{NOMENCLATURE}

$A^{(k)}$ : Magnetic vector potential of region $\mathrm{k}$

$B_{r}^{(k)} / B_{\alpha}^{(k)}$ : Radial / tangential flux density in region $\mathrm{k}[\mathrm{T}]$

$B_{/ /} / B_{\perp}$ : Major / minor axis of the flux density locus [T]

$F$ : Fundamental magnetic field frequency $[\mathrm{Hz}]$

$F_{i}$ : Iron loss frequency of the ring $i[\mathrm{~Hz}]$

$F_{\text {lim }}:$ Skin depth frequency $[\mathrm{Hz}]$

$G_{m}$ : Gear ratio

$J^{(k)}$ : Eddy current density in region $\mathrm{k}\left[\mathrm{A} / \mathrm{m}^{2}\right]$

$k$ : Index of the magnetic gear region

$K_{i}$ : Magnet splitting of the ring $i$ defined in Fig. 4

$L_{z}$ : Magnetic length of the magnetic gear [m]

$M^{(k)}$ : Radial magnetization distribution of region $\mathrm{k}$

$N_{\text {pos }}$ : Number of positions for the magnetic loss computation

$p_{\text {int }} / p_{\text {ext }}$ : Number of internal / external ring pole pairs

$P_{\text {iron }}^{(k)}$ : Instantaneous iron loss density in region $\mathrm{k}\left[\mathrm{W} / \mathrm{m}^{3}\right]$

M. Desvaux, H. Ben Ahmed and B. Multon are with SATIE, ENS Rennes, University of Bretagne Loire, CNRS, 35170 Bruz, France (e-mail: melaine.desvaux@ens-rennes.fr, bernard.multon@ens-rennes.fr).
$P_{E d d y}^{(k)}:$ Eddy current losses in region $\mathrm{k}[\mathrm{W}]$

$P_{r} / P_{\alpha}:$ Radial / tangential permeance

$Q$ : Number of ferromagnetic pole pieces

$R_{a v}^{(k)}$ : Average radius of region $\mathrm{k}[\mathrm{m}]$

$S_{P M}^{(k)}$ : Permanent magnet area of region $\mathrm{k}\left[\mathrm{m}^{2}\right]$

$U_{i, j}$ : Potential of the permeance network at point $i, j$

$\delta_{\text {int }} / \delta_{\text {ext }}:$ Internal / external airgap [m]

$\xi_{i, j}$ : Major axis angle of the flux density at point $i, j[\mathrm{rad}]$

$\theta^{(k)}$ : Angular position of the ring of region $\mathrm{k}$ [rad]

$\hat{\theta}_{\text {ext }}^{(k)}$ : Displacement amplitude of the external ring for the

average magnetic loss computation of region $\mathrm{k}$ [rad]

$\theta$ : Global angular position of the magnetic gear [rad]

$\theta_{i, j}^{*}$ : Global angular position maximizing flux density at the point $i, j[\mathrm{rad}]$

$\Omega^{(k)}$ : Rotational speed of the ring of region $\mathrm{k}[\mathrm{rad} / \mathrm{s}]$

$\sigma$ : Electrical conductivity of magnets [S]

$\phi_{r, i, j} / \phi_{\alpha, i, j}:$ Radial / tangential flux source at point $i, j$

$\tau_{\text {int }} / \tau_{\text {ext }}$ : Pole pitch of the internal / external ring [m]

$\Omega_{i / 0}$ : Rotational speed of the $\operatorname{ring} i[\mathrm{rad} / \mathrm{s}]$

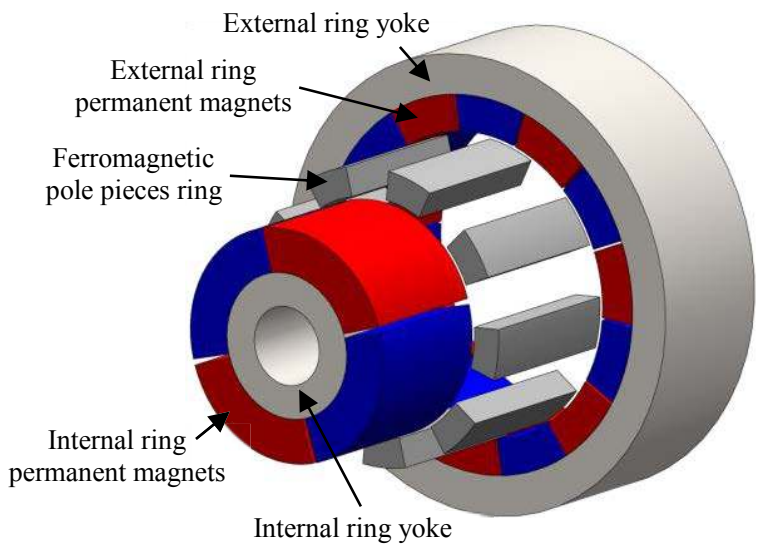

Fig. 1: Coaxial magnetic gear architecture in an exploded-view drawing with low pole numbers (i.e. $p_{\text {int }}=2, p_{\text {ext }}=7$, and $Q=9$ )

\section{INTRODUCTION}

Mechanical gearboxes, as currently used in drives, and electromechanical conversion chains provide for a smaller capital expenditure and lower mass than a direct

S. Sire is with University of Brest, FRE CNRS 3744, IRDL, 29200 Brest, France (e-mail: stephane.sire@univ-brest.fr).

S. Hlioui is with SATIE, CNAM, ENS Cachan, CNRS, 75141 Paris, France (e-mail: sami.hlioui@satie.ens-cachan.fr). 
drive conversion chain [1]. On the downside, mechanical gearboxes cause production interruptions and the need for repairs, thus increasing operating costs [2]. In this context, an attractive solution would consist of developing a conversion chain with a semi-fast generator and a magnetic gear [3]. The most popular topology of magnetic gears was proposed by Martin [4] and has been the topic of various studies conducted by Atallah [5][6] and others [7][8][9][10][11]. This magnetic gear structure, called coaxial (shown in Fig. 1), offers potentially high performance with a higher torque density and greater reliability than mechanical gearboxes [12]. The structure becomes even more attractive in high-torque applications, like a high-power wind turbine (on the order of several MN.m and several MW) [13].

The competitiveness of this magnetic gear must be evaluated with respect to wind turbine operations, with conversion chain efficiency and heat dissipation constituting the major criteria. Magnetic losses have already been computed using the finite element method [9][14], but computation time remains too high to integrate the magnetic loss computation into a set of models for a global mechatronic optimization of magnetic gears. Magnetic field hybrid analytical models proposed in [15] based on subdomain model [16][17] coupled with permeance network model [18] should allow to compute analytically the different magnetic losses (eddy current in magnets and iron losses). An optimization procedure adapted to the analytical computation of magnetic losses must also be proposed.

The major contribution of this article lies in the development of a fast computation of magnetic losses that incorporates both eddy current losses in permanent magnets and iron losses in laminated yokes and pole pieces based on a hybrid analytical model [15]. The magnetic loss computation model is based on the solution to Laplace's and Poisson's equations [16][17] for permanent magnets and yokes and moreover depends on the evolution of the magnetic field. For laminated pole pieces, a previous analytical model is coupled with a bi-directional permeance network model [18] in order to determine the magnetic field distribution. A classical loss computation method (used with a conventional electrical machine) is then performed to derive eddy current losses in permanent magnets [19] with a magnet splitting consideration and for iron losses by means of a spatial and temporal evaluation of the flux density in post-processing [20]. The analytical results obtained from these models will be compared with results from a finite element model in magnetostatics and magnetodynamics by considering both precision and computation time. Lastly, a biobjective mass efficiency optimization protocol, including magnetic loss models, is proposed for a $6-\mathrm{MW}$ and $12.5-\mathrm{rpm}$ magnetic gear.

\section{PRINCIPLE OF THE MAGNETIC GEAR}

The coaxial magnetic gear [5] shown in Fig. 1 is composed of three magnetic parts: an internal ring with $p_{i n t}$ pole pairs of permanent magnets and a ferromagnetic yoke; an external ring with $p_{\text {ext }}$ pole pairs of permanent magnets and a ferromagnetic yoke; and a ring with $\mathrm{Q}$ ferromagnetic poles between the two permanent magnet rings (an example is provided in Fig. 1 with low pole numbers, to improve readability: $p_{\text {int }}=2, p_{\text {ext }}=7$, and $Q=9$ ). To achieve power transmission, the pole numbers of the three rings must respect Eq. (1).

$$
p_{\text {int }}+p_{\text {ext }}=Q
$$

Depending on the fixed ring, the gear ratio $G_{m}$ is given by (2), where $\Omega_{\text {int } / 0}, \Omega_{\text {ext } / 0}$ and $\Omega_{Q / 0}$ are the rotational speeds of the internal ring, external ring and pole piece ring, respectively. The fundamental magnetic field frequency $F$ is then given by (3). To compute the magnetic field distribution in the magnetic gear, the fixed ring is not needed; the analytical magnetostatic model presented in the next section is thus available regardless of the fixed ring.

$$
\begin{gathered}
\Omega_{\text {int } / 0}=0 \rightarrow G_{m}=\frac{\Omega_{\text {ext } / 0}}{\Omega_{Q / 0}}=\frac{Q}{p_{\text {ext }}} \\
\Omega_{Q / 0}=0 \rightarrow G_{m}=\frac{\Omega_{\text {int } / 0}}{\Omega_{\text {ext } / 0}}=-\frac{p_{\text {ext }}}{p_{\text {int }}} \\
\Omega_{\text {ext } / 0}=0 \rightarrow G_{m}=\frac{\Omega_{\text {int } / 0}}{\Omega_{Q / 0}}=\frac{Q}{p_{\text {int }}} \\
\Omega_{\text {int } / 0}=0 \rightarrow F=\frac{\left|p_{\text {ext }} \cdot \Omega_{\text {ext } / 0}\right|}{2 \pi}=\frac{\left|Q \cdot \Omega_{Q / 0}\right|}{2 \pi} \\
\Omega_{Q / 0}=0 \rightarrow F=\frac{\left|p_{\text {int }} \cdot \Omega_{\text {int } / 0}\right|}{2 \pi}=\frac{\left|p_{\text {ext }} \cdot \Omega_{\text {ext } / 0}\right|}{2 \pi} \\
\mid \Omega_{\text {ext } / 0}=0 \rightarrow F=\frac{\left|p_{\text {int }} \cdot \Omega_{\text {int } / 0}\right|}{2 \pi}=\frac{\left|Q \cdot \Omega_{Q / 0}\right|}{2 \pi}
\end{gathered}
$$

\section{HyBRID ANALYTICAL MAGNETOSTATIC MODEL}

\section{A. Magnetic field resolution elsewhere than pole pieces}

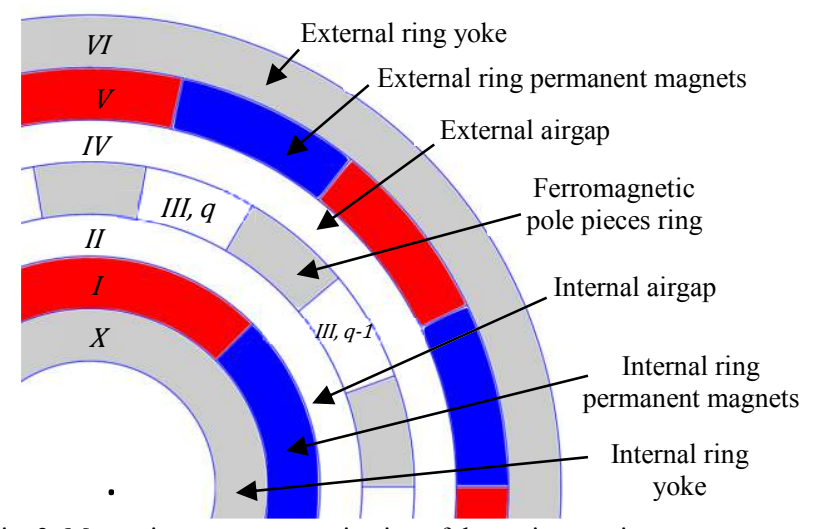

Fig. 2: Magnetic gear parameterization of the various regions

To evaluate the magnetic losses in permanent magnets and yokes of the magnetic gear, it is first necessary to determine the magnetic field distribution across the various regions of the system, as presented in Fig. 2. For this computation, a 2D magnetostatic model, developed by [16] without any magnetic field computation in the yokes and by [17] with such a computation in the yokes, has been applied along with: the radial magnetization of magnets, a constant remanence of the magnets, and a constant relative permeability for all materials. This analytical model requires solving Poisson's and Laplace's equations (4) in the k region of the system (i.e. yoke region, permanent magnet region, air gap region, and each air space 
between pole pieces), where $A^{(k)}$ and $M^{(k)}$ are the magnetic vector potential and radial magnetization distribution, respectively; $r$ and $\alpha$ are the cylindrical coordinates.

$$
\frac{\partial^{2} A^{(k)}}{\partial r^{2}}+\frac{1}{r} \frac{\partial A^{(k)}}{\partial r}+\frac{\partial^{2} A^{(k)}}{\partial \alpha^{2}}=\left\{\begin{array}{c}
-\frac{1}{r} \frac{\partial M^{(k)}}{\partial \alpha} \\
0
\end{array}\right.
$$

From boundary conditions defined [17], it is possible to obtain the magnetic potential vector $A^{(k)}$, radial flux $B_{r}^{(k)}$ and tangential flux $B_{\alpha}^{(k)}$ in the different magnetic gear regions. With this analytical model, the magnetic field distribution is computed for just a single global position of the magnetic gear. To derive the magnetic losses, it then becomes necessary to compute the magnetic field distribution many times over for various global positions, representing one magnetic cycle of the system. As regards iron losses in the pole pieces, since the analytical model precludes any magnetic field computation in these regions, coupling with a bi-directional reluctance network model is required to determine the flux density distribution.

\section{B. Magnetic field resolution in a pole piece resulting from coupling with a permeance network model}

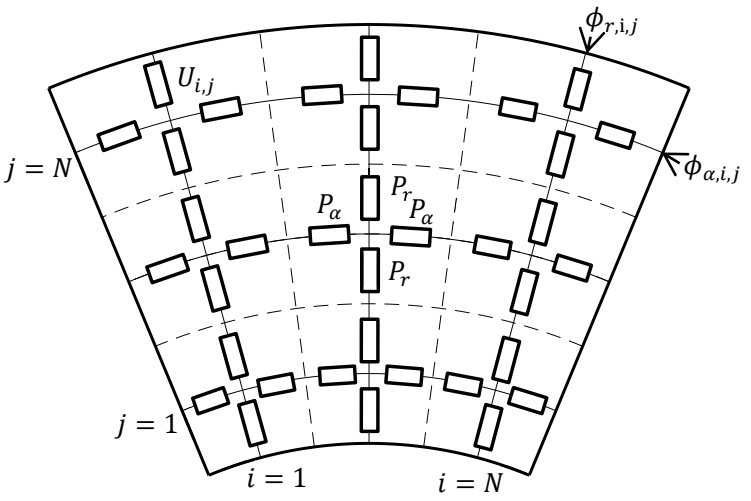

Fig. 3: Pole piece parameterization for the $N^{*} N$ permeance network model

To compute iron losses in laminated pole pieces like in [20], for just one laminated pole piece, it is possible to determine the flux density distribution resulting from coupling between the analytical model based on Maxwell's equation [17] and the permeance network model, as shown in Fig. 3 with a low permeance number. To compute the flux density distribution in a laminated pole piece, a constant radial and tangential mesh has been adopted, and the permeance values are computed like in [21]. The radial and angular discretizations are then set equal in order to obtain an $N * N$ permeance network.

The coupling between both analytical models is performed on the pole piece boundaries, where the flux sources $\phi_{r, i, j}$ and $\phi_{\alpha, i, j}$ of the reluctance network model are determined by (5), and where $A^{(k)}$ correspond to the potential vector determined in regions II, III and IV from the model described in section IVA. To identify the flux in the radial and tangential permeances of the network, Eq. (6) must be solved at the various nodes (the potentials $U_{i, j}$ are the unknowns of this problem). If a node is adjacent to the pole piece boundary, then different terms in (6) must be substituted by the flux sources in (5), as displayed in (7) for specific values of $i$ and $j$.

$$
\begin{gathered}
\left\{\begin{array}{l}
\phi_{r, i, j}=\left(A^{(k)}\left(r_{i}, \alpha_{i+1}\right)-A^{(k)}\left(r_{i}, \alpha_{i}\right)\right) L \\
\phi_{\alpha, i, j}=\left(A^{(k)}\left(r_{i+1}, \alpha_{i}\right)-A^{(k)}\left(r_{i}, \alpha_{i}\right)\right) L
\end{array}\right. \\
\left(U_{i, j}-U_{i-1, j}\right) 2 \cdot P_{\alpha}+\left(U_{i, j}-U_{i, j-1}\right) 2 \cdot P_{r}+ \\
\left(U_{i, j}-U_{i+1, j}\right) 2 . P_{\alpha}+\left(U_{i, j}-U_{i, j+1}\right) 2 . P_{r}=0 \\
\left(U_{i, j}-U_{i-1, j}\right) 2 \cdot P_{\alpha}=\phi_{\alpha, i, j} \leftarrow i=1 \\
\left(U_{i, j}-U_{i+1, j}\right) 2 \cdot P_{\alpha}=\phi_{\alpha, i, j} \leftarrow i=N \\
\left(U_{i, j}-U_{i, j-1}\right) 2 \cdot P_{r}=\phi_{r, i, j} \leftarrow j=1 \\
\left(\left(U_{i, j}-U_{i, j+1}\right) 2 \cdot P_{r}=\phi_{r, i, j} \leftarrow j=N\right.
\end{gathered}
$$

It then becomes possible to derive a matrix system (8) from these equations, where: $[U]$ is the potential matrix (containing the problem unknowns), $[P]$ the permeance matrix, and $[\phi]$ the flux matrix (containing the flux found from Maxwell's equation). The potential matrix $[U]$ can thus be determined from an inversion of matrix $[P]$. This numerical operation yields the radial flux $B_{r, i, j}$ and tangential flux $B_{\alpha, i, j}$ using (9). To compute the iron losses in pole pieces, the pole piece permeance network will include $20 * 20$ nodes. This configuration permits to have a low computation time for the permeance network resolution, compared to the global iron loss computation time (lower than $5 \%$ of the global computation time), without impacting the precision of the iron loss computation (i.e. this difference is less than $1 \%$ with an iron loss computation in pole pieces including 50*50 nodes).

$$
\begin{gathered}
{[P]_{N * N, N * N} *[U]_{N * N, 1}=[\phi]_{N * N, 1}} \\
B_{r, i, j}=\frac{1}{r_{i} \frac{\beta}{N} L}\left(\begin{array}{c}
\left(U_{i, j}-U_{i, j-1}\right) 2 . P_{r}+ \\
\left(U_{i, j+1}-U_{i, j}\right) 2 . P_{r}
\end{array}\right) \\
B_{\alpha, i, j}=\frac{1}{\frac{R_{M}^{(I I I)}-R_{m}^{(I I I)}}{N} L}\left(\begin{array}{c}
\left(U_{i, j}-U_{i-1, j}\right) 2 . P_{\alpha}+ \\
\left(U_{i+1, j}-U_{i, j}\right) 2 . P_{\alpha}
\end{array}\right)
\end{gathered}
$$

\section{EDDY CURRENT LOSSES IN PERMANENT MAGNETS}

\section{A. Eddy current determination from the analytical model}

To rigorously compute the eddy current losses in permanent magnets, it is necessary to solve the scattering equation in both regions of permanent magnets (10), where $\theta^{(k)}$ is the angular position of the permanent magnet rings $(k=I$ or $k=V)$. In this article, it is considered that the magnetic reaction of the eddy current on the magnetic field distribution is negligible in comparison with magnetostatic induction [19]. This consideration is equivalent to considering a skin depth greater than the magnet thickness. The eddy current loss computation can thus be decoupled from the magnetic field computation. The magnetic field distribution is then computed in magnetostatics [17], as described in the previous section, while the eddy current $J^{(k)}$ is computed by (11) for the two permanent magnet rings, whose eddy current source term $J_{0}^{(k)}$ leads to imposing a total axial current in the magnet equal to zero (12). The eddy current losses in a single magnet are determined in both permanent magnet regions using (13), with $k=I$ and $V$. 
TABLE I:

DATA FOR THE EXAMPLE IN SECTIONS V AND VI

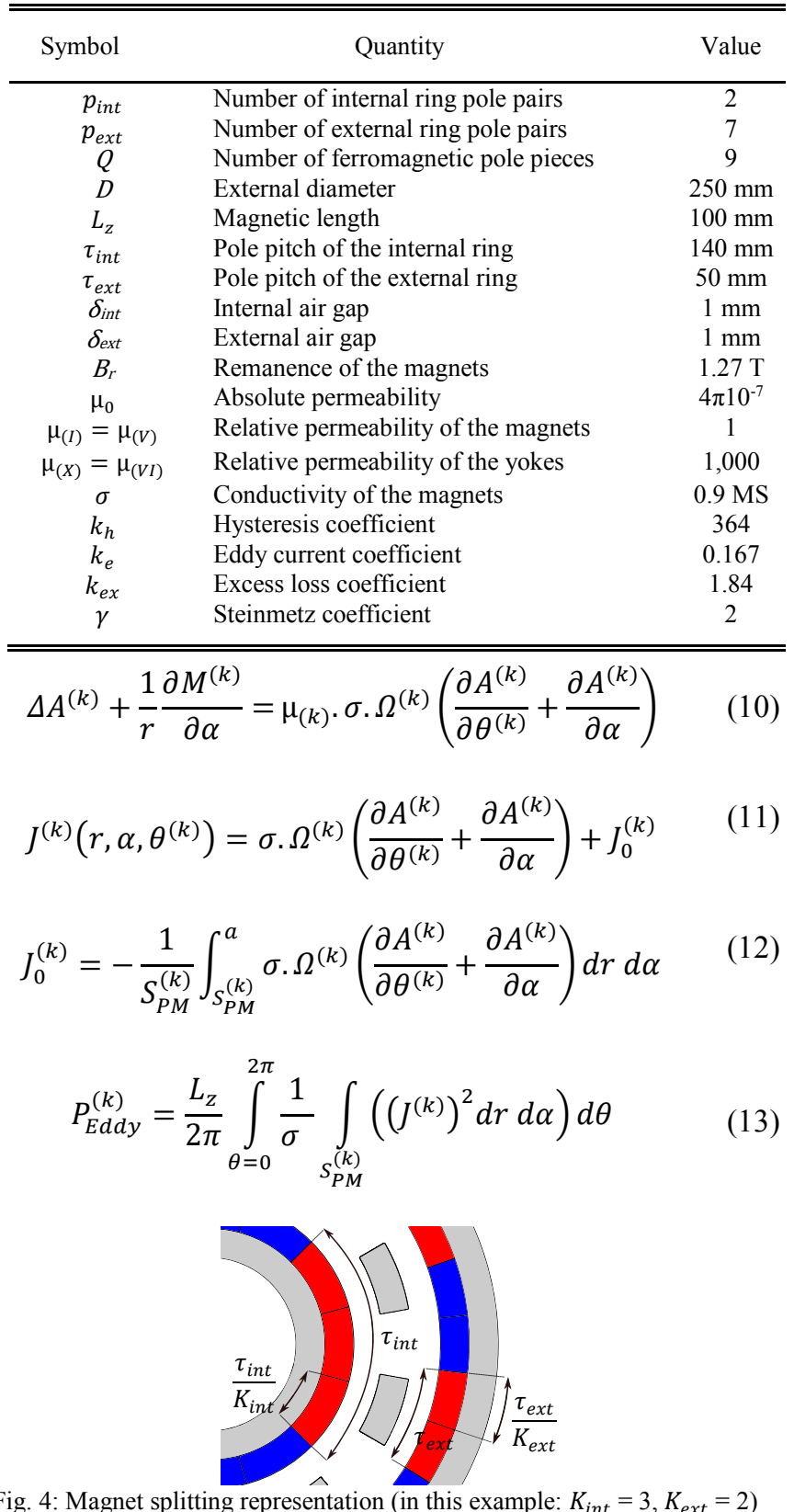

\section{B. Magnets splitting consideration}

The eddy current losses in magnets can be reduced if the magnets are split into $K_{\text {int }}$ parts for the internal ring and $K_{\text {ext }}$ parts for the external ring [22]. $K_{\text {int }}$ and $K_{\text {ext }}$ correspond to the ratio of the pole pitch to the permanent magnet width for the internal and external rings, respectively, as defined in Fig. 4 with $K_{\text {int }}=3$ and $K_{\text {ext }}=2$ and with $\tau_{\text {int }}$ and $\tau_{\text {ext }}$ as defined in (14). The configuration used to analyze the evolution of eddy current losses comprises a fixed pole-piece ring, which implies that the high-speed rotor corresponds to the internal ring while the low-speed rotor corresponds to the external ring. Integrating splitting into the analytical model solely entails dividing the angular integration terminals as a function of splitting (shown in (15) for the internal ring). Fig. 5 presents the loss percentage of transmitted power vs. the splitting of the magnets with a rotational speed of $350 \mathrm{rpm}$ for the high-speed rotor and 100 rpm for the low-speed rotor, given the magnetic gear presented in Table I.

$$
\begin{gathered}
\tau_{\text {int }}=\frac{2 \pi R_{a v}^{(I)}}{2 \cdot p_{\text {int }}} \\
\tau_{\text {ext }}=\frac{2 \pi R_{a v}^{(V)}}{2 \cdot p_{\text {ext }}} \\
\alpha \in\left[\theta^{(I)}, \theta^{(I)}+\frac{\tau_{\text {int }}}{K_{\text {int }}}\right]
\end{gathered}
$$

Fig. 5 indicates that the eddy current losses in permanent magnets decrease significantly with splitting for the external ring and more slowly for the internal ring, according to the example presented in Table I. The splitting of the magnets is therefore a key parameter in obtaining a high-efficiency magnetic gear.

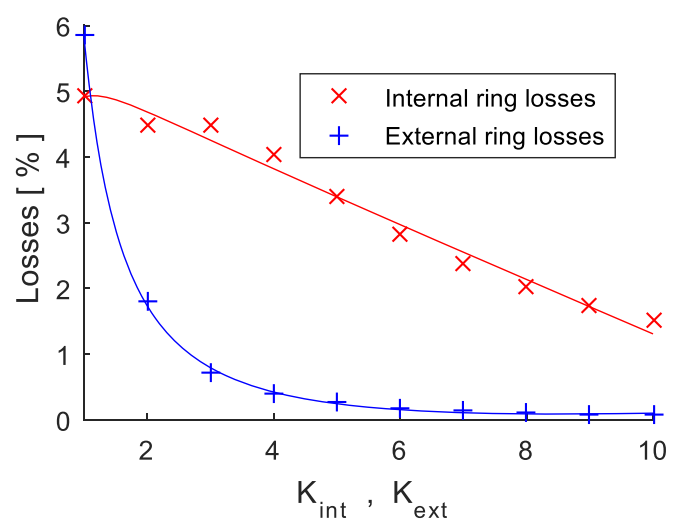

Fig. 5: Eddy current loss percentages of the transmitted power vs. splitting of the magnets with a rotational speed of $350 \mathrm{rpm}$ for the high speed rotor and 100 rpm for the low speed rotor for the magnetic gear presented in Table I.

\section{Validation of the magnetostatic model using a magnetodynamic finite element model}

In order to validate the eddy current loss model in permanent magnets presented in the previous section, the results obtained with this magnetostatic analytical model are compared with other results from a 2D transient finite element model, with a magnetodynamic model being proposed for the example described in Table I. The studied configuration corresponds to a fixed pole-piece ring. It is commonly accepted that the skin effect begins to have an impact on the magnetic field distribution (i.e. on losses) when the rotational speed produces an equality between skin thickness and half the pole pitch [19]. From this point forward, results obtained with the analytical model presented in the previous section will differ from those obtained using ANSYS, a 2D magnetodynamic finite element model.

For the magnetic gear defined in Table I, without any splitting of magnets, this phenomenon is first observed for the high-speed rotor when the fundamental magnetic field frequency $F=55 \mathrm{~Hz}$ (which corresponds to a rotational speed of 1,680 rpm for the high-speed rotor and $480 \mathrm{rpm}$ for the lowspeed rotor). A comparison between results obtained with the magnetostatic analytical model and those with the 2D magnetodynamic finite element model can be drawn for various fundamental magnetic field frequencies $F$ (3) with $\Omega_{Q / 0}=0$, as indicated in Fig. 6. 
This comparison reveals a good correlation between the two models for frequencies $F$ of less than approx. $50 \mathrm{~Hz}$. In contrast, for frequencies of $50 \mathrm{~Hz}$ or more, the hypothesis of a negligible magnetic reaction of the eddy current on the magnetic field distribution no longer appears to be valid. This outcome was to be anticipated since the equality between skin thickness and the half-pole pitch is achieved for a fundamental magnetic field frequency $F=55 \mathrm{~Hz}$. It is thus possible to define a validity criterion for the magnetostatic analytical model of eddy current losses in permanent magnets. Such a criterion would be satisfied whenever frequencies are below the limit frequency $F_{\text {lim }}$ (16) obtained with a skin thickness equal to the smaller half-pole pitch of the two permanent magnet rings as a function of splitting. Due to the necessity to have a high efficiency, the splitting of the magnets will be significant, and the magnetostatic model will always remain valid.

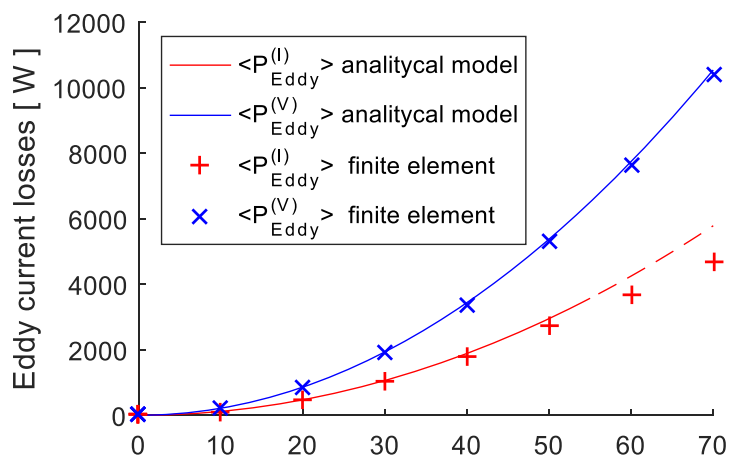

Fundamental magnetic field frequency $\mathrm{F}$ [ $\mathrm{Hz}$ ]

Fig. 6: Comparison of results obtained with the magnetostatic analytical model and the 2D magnetodynamic finite element model, for the example presented in Table I

$$
\begin{gathered}
F_{\text {lim }}=\min \left(F_{\text {lim int }}, F_{\text {lim ext }}\right) \\
F_{\text {lim int }}=\frac{4}{\mu_{(I)} \cdot \sigma \cdot \pi}\left(\frac{K_{\text {int }}}{\tau_{\text {int }}}\right)^{2} \\
\left(F_{\text {lim ext }}=\frac{4}{\mu_{(V)} \cdot \sigma \cdot \pi}\left(\frac{K_{\text {ext }}}{\tau_{\text {ext }}}\right)^{2}\right.
\end{gathered}
$$

\section{IRON LOSSES IN FERROMAGNETIC PARTS}

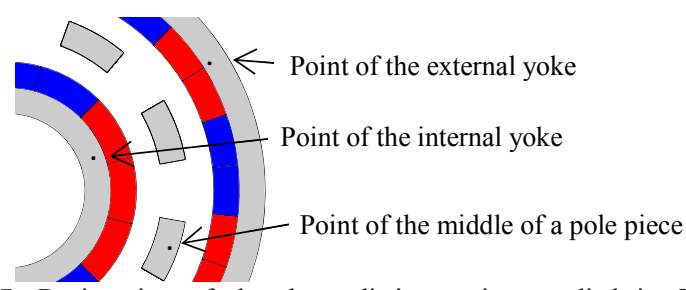

Fig. 7: Designation of the three distinct points studied in Section VI, representing the magnetic field evolution of the three regions

\section{A. Flux density evolution}

Both temporal and spatial variations of the flux density generate iron losses in the different ferromagnetic regions. To determine whether a ferromagnetic region is subjected to significant iron losses, it is suggested to draw the flux density evolution in a $2 \mathrm{D} B_{r}, B_{\alpha}$ plane. The locus of the various ferromagnetic parts must then be analyzed in order to better understand the iron loss evolution, as presented in [15]. Fig. 7 designates three distinct points chosen to analyze the magnetic field evolution of these three regions.

$$
\begin{gathered}
F_{\text {int }}=\frac{p_{\text {int }} \cdot \Omega_{\text {int } / 0}}{2 \pi} \cdot \frac{Q}{p_{\text {int }}}=\frac{p_{\text {ext }} \cdot \Omega_{\text {ext } / 0}}{2 \pi} \cdot \frac{Q}{p_{\text {int }}} \\
F_{Q}=\frac{p_{\text {int }} \cdot \Omega_{\text {int } / 0}}{2 \pi}=\frac{p_{\text {ext }} \cdot \Omega_{\text {ext } / 0}}{2 \pi} \\
F_{\text {ext }}=\frac{p_{\text {int }} \cdot \Omega_{\text {int } / 0}}{2 \pi} \cdot \frac{Q}{p_{\text {ext }}}=\frac{p_{\text {ext }} \cdot \Omega_{\text {ext } / 0}}{2 \pi} \cdot \frac{Q}{p_{\text {ext }}} \\
F_{Q}<F_{\text {ext }}<F_{\text {int }}
\end{gathered}
$$
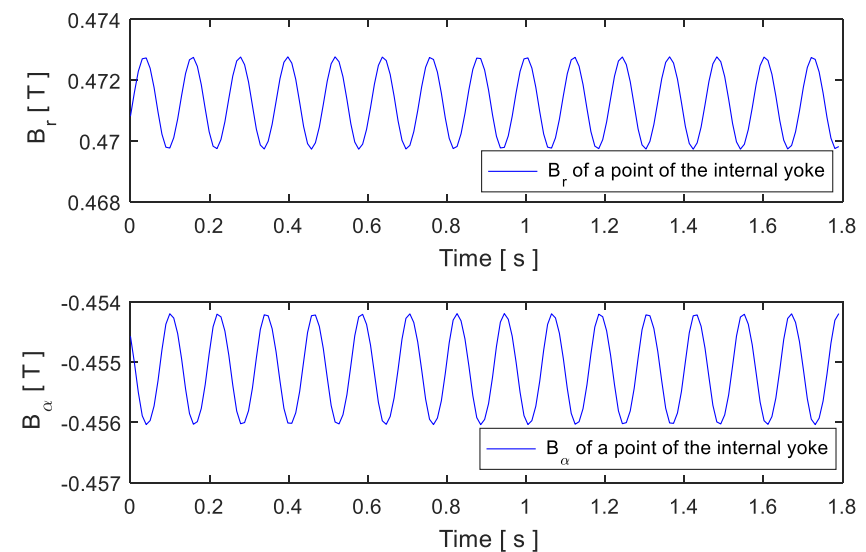

(a)
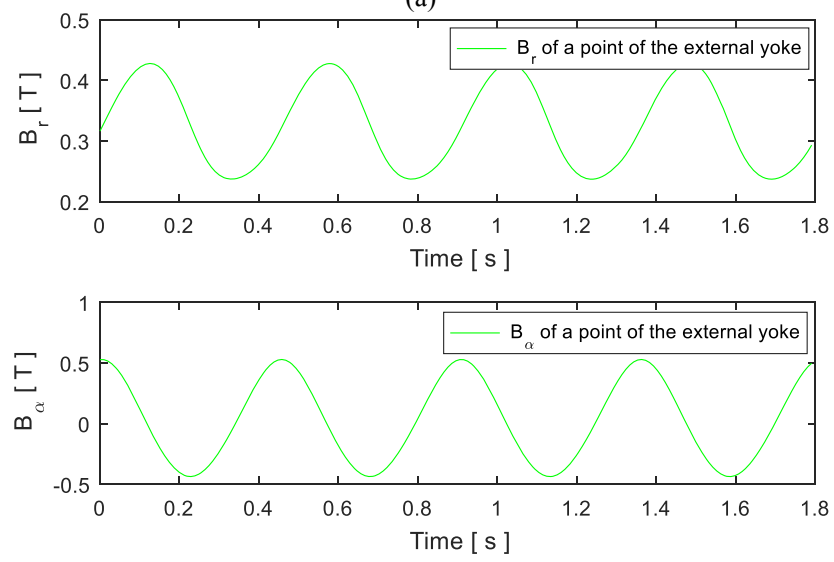

(b)
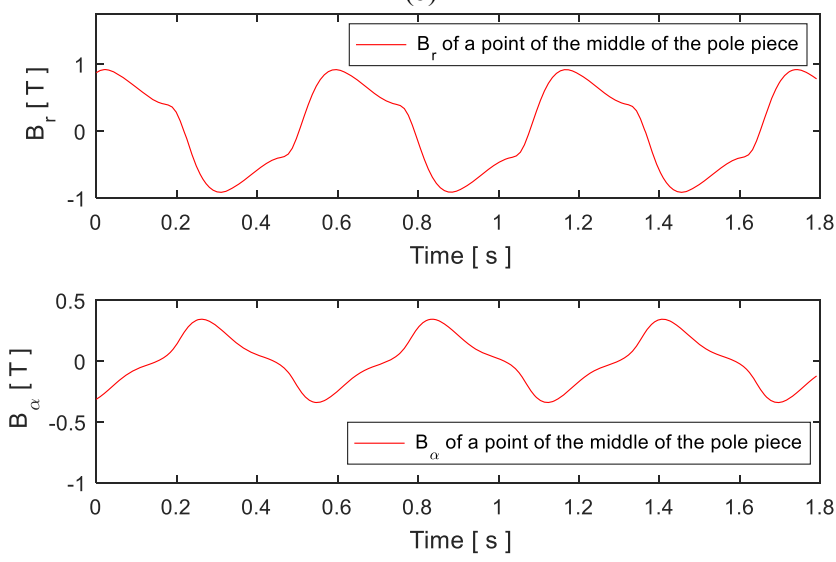

(c)

Fig. 8: Evolution in the radial and tangential components of flux density when the magnetic gear is in rotation and when the fixed ring is the pole piece ring for the points displayed in Fig. 7 on the: a) internal yoke, b) external yoke, and c) pole piece

As shown in Fig. 8 for the internal yoke, external yoke and pole pieces, the locus generation frequencies differ (Fig. 8a 
corresponds to the point of the internal yoke, Fig. $8 \mathrm{~b}$ to the point of the external yoke and Fig. $8 \mathrm{c}$ to the point of the pole piece). The locus generation frequency for the various ferromagnetic parts thus depends on both rotational speed and pole configuration, as described in Eqs. (17) and (18). According to Fig. 9, the locus for the various points indicated in Fig. 7 may be derived from the curve plotted in Fig. 8 (Fig. 9a references the point of the internal yoke, Fig. $9 \mathrm{~b}$ the point of the external yoke, and Fig. 9c the point of the middle of a pole piece). The spatial variations of flux density displayed in Fig. 9 confirm the need to include spatial variation in the iron loss computation method [15].

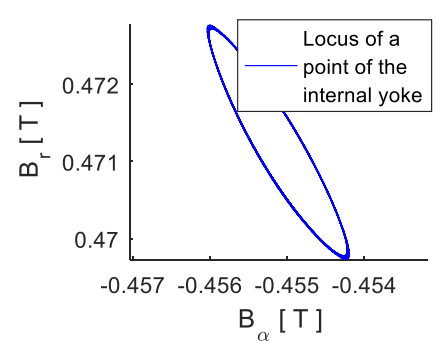

(a)

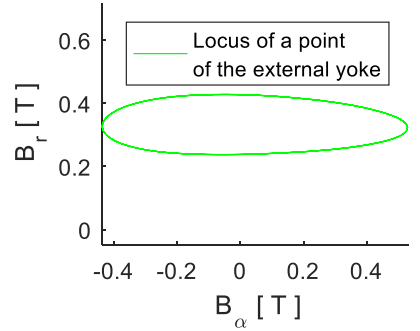

(b)

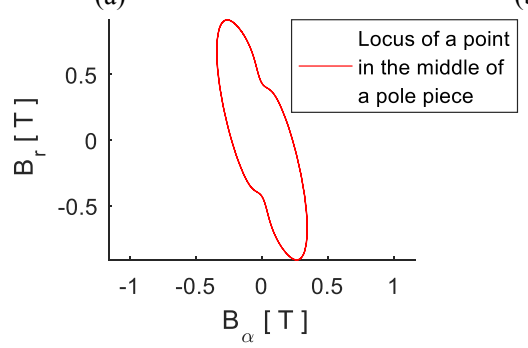

(c)

Fig. 9: Spatial variations in flux density for the points displayed in Fig. 7 on the: a) internal yoke, b) external yoke, and c) pole piece (presented in Fig. 8)

As seen in Fig. 9, the largest locus is obtained in the pole piece since pole pieces are subjected to a rotating magnetic field, imposed by permanent magnet rings. Fig. 9 also reveals that the locus obtained in the external yoke is higher than that in the internal yoke since the magnetic field distribution is apparently being imposed by the internal ring. Even though frequency is greater for the locus in the internal yoke (18), iron losses in pole pieces will still be higher than those in yokes.

\section{B. Iron loss computation}

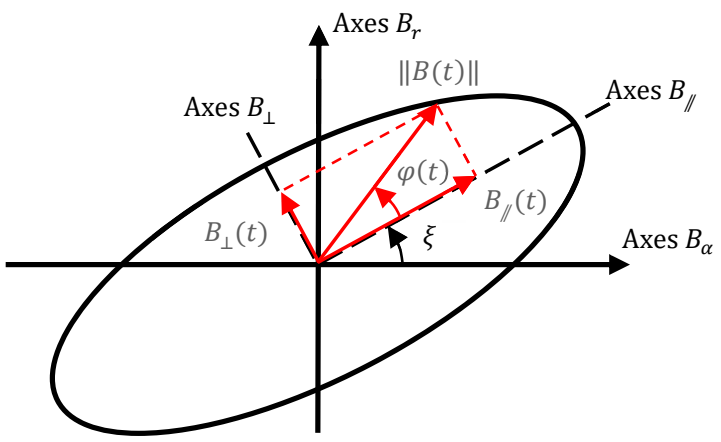

Fig. 10: Locus parameterization for the iron loss evaluation

Both $B_{/ /}$, the major axis of the flux density locus, and $B_{\perp}$, the minor axis of the flux density locus (as defined in Fig. 10), must be determined in order to evaluate the iron losses in both yokes and pole pieces [20]. It is therefore necessary to compute the magnetic field distribution using the global analytical model presented above (i.e. Maxwell's equation coupled with the permeance network model) for one magnetic cycle. The next step consists of evaluating the norm of the flux $\left\|B\left(r_{j}, \alpha_{i}, \theta\right)\right\|$ everywhere in the ferromagnetic parts for the different magnetic cycle positions. For the various points $\left(r_{j}, \alpha_{i}\right)$ of the ferromagnetic parts, $B_{/ /}$and $B_{\perp}$ are identified using Eq. (19), where $\varphi_{i, j}(\theta)$ is defined in Fig. 10 and Eq. (20), the major axis angle of the flux density $\xi_{i, j}$ is determined from (21), and $\theta_{i, j}^{*}$ correspond to the global angular position maximizing flux density at the point $\left(r_{j}, \alpha_{i}\right)$ [15][23].

$$
\begin{gathered}
\left\{\begin{array}{l}
B_{/ /}\left(r_{j}, \alpha_{i}, \theta\right)=\left\|B\left(r_{j}, \alpha_{i}, \theta\right)\right\| \cdot \cos \left(\varphi_{i, j}(\theta)\right) \\
B_{\perp}\left(r_{j}, \alpha_{i}, \theta\right)=\left\|B\left(r_{j}, \alpha_{i}, \theta\right)\right\| \cdot \sin \left(\varphi_{i, j}(\theta)\right)
\end{array}\right. \\
\varphi_{i, j}(\theta)=\arctan \left(\frac{B_{r}\left(r_{j}, \alpha_{i}+\theta\right)}{B_{\alpha}\left(r_{j}, \alpha_{i}+\theta\right)}\right)-\xi_{i, j} \\
\xi_{i, j}=\arctan \left(\frac{B_{r}\left(\theta_{i, j}^{*}\right)}{B_{\alpha}\left(\theta_{i, j}^{*}\right)}\right)
\end{gathered}
$$

The instantaneous iron loss density $P_{\text {iron }}$ can then be evaluated from Eq. (22), where $k_{h}, k_{e}$ and $k_{e x}$ are the hysteresis coefficient, eddy current coefficient and excess loss coefficient, respectively, and $\gamma$ the Steinmetz coefficient [24]. In Eq. (22), $F$ corresponds to: $F_{\text {int }}$ for the internal yoke iron loss computation, $F_{Q}$ for the pole piece iron loss computation, and $F_{\text {ext }}$ for the external yoke iron loss computation (in accordance with (17)).

$$
\begin{aligned}
P_{\text {iron }}^{(k)}\left(r_{j}, \alpha_{i}\right)= & k_{h} . F \cdot\left(\left(\frac{\Delta B_{\perp}}{2}\right)^{\gamma}+\left(\frac{\Delta B_{/ /}}{2}\right)^{\gamma}\right) \\
& +k_{e} \frac{1}{T} \int_{t=0}^{T}\left(\left(\frac{d B_{\perp}}{d t}\right)^{2}+\left(\frac{d B_{/ /}}{d t}\right)^{2}\right) d t \\
& +k_{\text {ex }} \frac{1}{T} \int_{t=0}^{T}\left(\left(\frac{d B_{\perp}}{d t}\right)^{2}+\left(\frac{d B_{/}}{d t}\right)^{2}\right)^{3 / 4} d t
\end{aligned}
$$

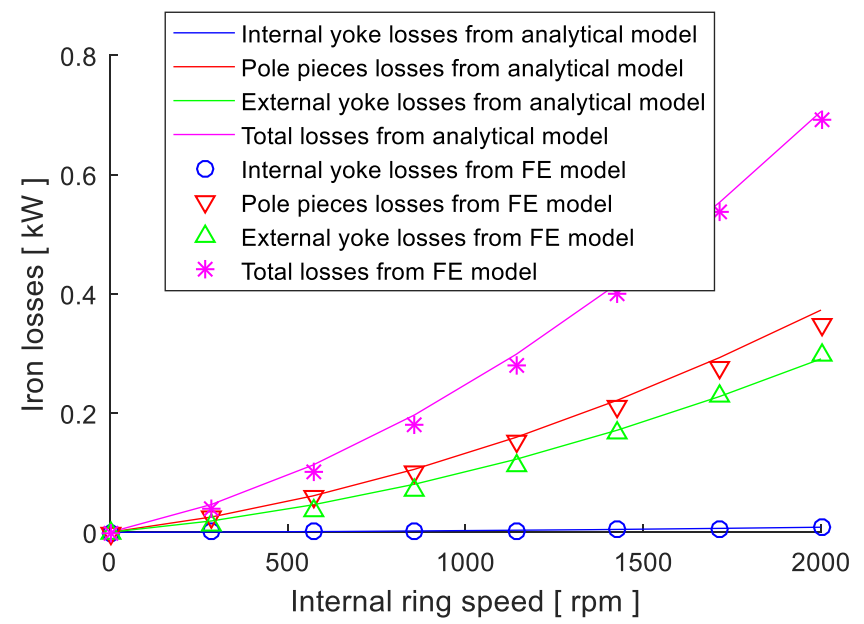

Fig. 11: Comparison between results obtained with the magnetostatic analytical model of the magnetic field distribution and those with a 2D magnetostatic finite element model for the magnetic gear presented in Table I 
Fig. 11 shows the evolution in the various iron losses as a function of the internal ring speed (when the pole piece ring is fixed), with a laminated steel of grade M1000-65 (linear properties have been assumed) and with the iron loss coefficient proposed in [25], for the magnetic gear described in Table I. Fig. 11 also provides a comparison between results obtained with the magnetostatic hybrid analytical model of the magnetic field distribution and those with a 2D magnetostatic finite element model. The iron loss computation in pole pieces from the hybrid analytical model gives a result quite different from that found with the finite element model because the magnetic field can only handle two directions (radial and tangential) for the various nodes. These results validate the hybrid analytical model for the magnetic field distribution and allow concluding that iron losses in the internal yoke are negligible.

\section{COMPUTATION TIME ANALYSIS}

The studies conducted in this section have been based on an example with a high pole number, as described in Table II, which corresponds to a magnetic gear optimized for wind turbine applications (3.9 MW and $15 \mathrm{rpm}$ ) [3], with the same values of $k_{h}, k_{e}, k_{e x}, \gamma, \sigma$ and $B_{r}$ than the magnetic gear presented in Table I.

\section{A. Periodicity of the various magnetic losses}

As shown in Fig. 8, it is impossible to compute iron losses in the various parts using the same periodicity. The loss computations can thus be performed separately for these ferromagnetic parts, according to an external ring displacement amplitude for the entire range of magnetic loss computations given in (23).

To compute the average eddy current losses in permanent magnets, it is theoretically necessary to run the computation on one magnetic cycle of the magnetic field, corresponding to: $\hat{\theta}_{\text {ext }}^{(I)}=\hat{\theta}_{\text {ext }}^{(V)}=180 / C_{f}=180^{\circ}$, where $\hat{\theta}_{\text {ext }}^{(k)}$ denotes the external ring displacement amplitude (the various regions have been defined in Fig. 2), and $C_{f}$ the cogging torque factor. However, as shown in Fig. 12 at the rated speed, the instantaneous eddy current losses for both permanent magnet rings have an evolution with sub-periodicities lower than the magnetic cycle periodicity.

Due to these sub-periodicities, the computation of average eddy current losses requires a large number of intermediate positions $N_{\text {pos }}$ provided the computation is performed for one magnetic cycle of the magnetic field. To minimize the number of intermediate positions $N_{\text {pos }}$ (and hence the computation time) of these loss computations while maintaining adequate computational precision, the external ring displacement has been set equal to: $\hat{\theta}_{\text {ext }}^{(I)}=\hat{\theta}_{\text {ext }}^{(V)}=\pi / p_{\text {int }}$ (23) (see Fig. 12).

$$
\begin{gathered}
\hat{\theta}_{\text {ext }}^{(X)}=\frac{2 \pi}{p_{\text {ext }}} \cdot \frac{Q}{p_{\text {int }}}, \quad \hat{\theta}_{\text {ext }}^{(I I I)}=\frac{2 \pi}{p_{\text {ext }}}, \quad \hat{\theta}_{\text {ext }}^{(V I)}=\frac{2 \pi}{Q} \\
\hat{\theta}_{\text {ext }}^{(I)}=\hat{\theta}_{\text {ext }}^{(V)}=\frac{\pi}{p_{\text {int }}}
\end{gathered}
$$

TABLE II:

DATA FOR THE EXAMPLE IN SECTIONS VII

\begin{tabular}{clc}
\hline \hline Symbol & \multicolumn{1}{c}{ Quantity } & Value \\
\hline$p_{\text {int }}$ & Number of internal ring pole pairs & 20 \\
$p_{\text {ext }}$ & Number of external ring pole pairs & 131 \\
$Q$ & Number of ferromagnetic pole pieces & 151 \\
$D$ & External diameter & $4 \mathrm{~m}$ \\
$L_{z}$ & Magnetic length & $2.1 \mathrm{~m}$ \\
$N_{l}$ & Rated speed of the low-speed rotor & $15 \mathrm{rpm}$ \\
$F$ & Rated magnetic field frequency & $33 \mathrm{~Hz}$ \\
$\tau_{\text {int }}$ & Pole pitch of the internal ring & $275 \mathrm{~mm}$ \\
$\tau_{\text {ext }}$ & Pole pitch of the external ring & $44 \mathrm{~mm}$ \\
$\delta_{i n t}$ & Internal air gap & $5 \mathrm{~mm}$ \\
$\delta_{\text {ext }}$ & External air gap & $5 \mathrm{~mm}$ \\
\hline \hline
\end{tabular}

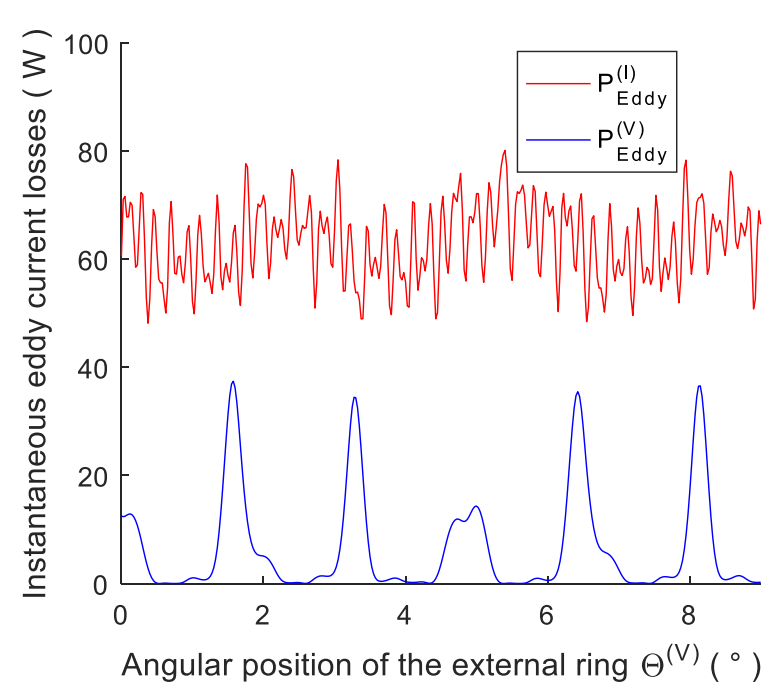

Fig. 12: Evolution in eddy current losses in a single magnet with internal and external permanent magnet rings vs. the external ring position for the example presented in Table II at the rated speed

\section{B. Consideration of a limited harmonic number}

Due to the high pole number of the studied example, which increases the matrix system dimension of the analytical model, along with the need to compute magnetic losses using a stepby-step process, the computation time for the loss evaluation in the magnetic gears is quite high. For the magnetic gear presented in Table II, the loss computation time equals $96 \mathrm{~h}$ with the finite element method yet without computing iron losses in the internal yoke (as reflected in Fig. 11), using an Intel Xeon E5-1630 v3, 8 threads, $3.70 \mathrm{GHz}$. In contrast, with the hybrid analytical model proposed in this paper, the magnetic loss computation time drops to $48 \mathrm{~h}$. For both these methods, the number of positions taken into account was $N_{\text {pos }}=150$.

To reduce computation time, [17] proposed a harmonics selection method that enables building the matrix system of the analytical model based on Maxwell's equations with only harmonics which generate magnetic fields. The most attractive harmonics selection methods take into account: the impaired harmonics of permanent magnet rings, the fundamental components of internal and external rings modulated by pole piece ring harmonics (e.g. harmonics with a periodicity of $\left.\left(3 . Q-p_{\text {int }}\right) .2 \pi\right)$, and the impaired harmonics of both internal and external rings modulated by the pole piece ring fundamental (e.g. harmonics with a periodicity of $(Q-$ 3. $\left.\left.p_{\text {int }}\right) .2 \pi\right)$. 


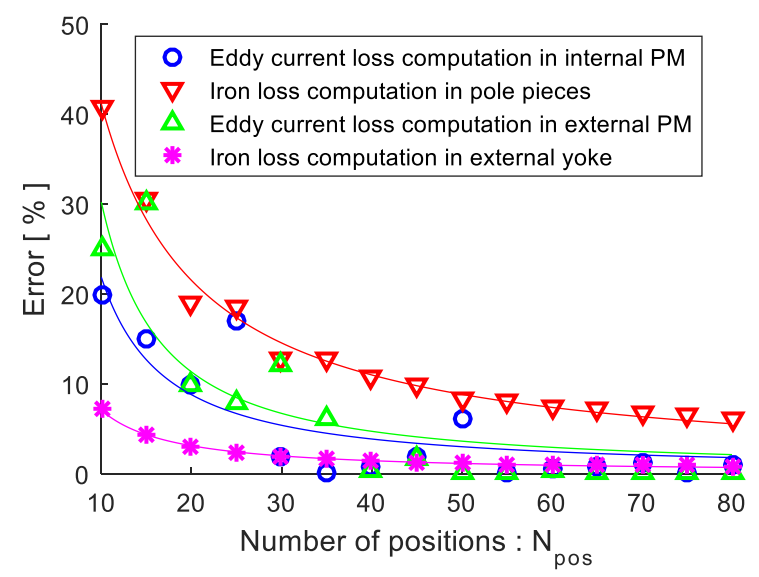

(a)

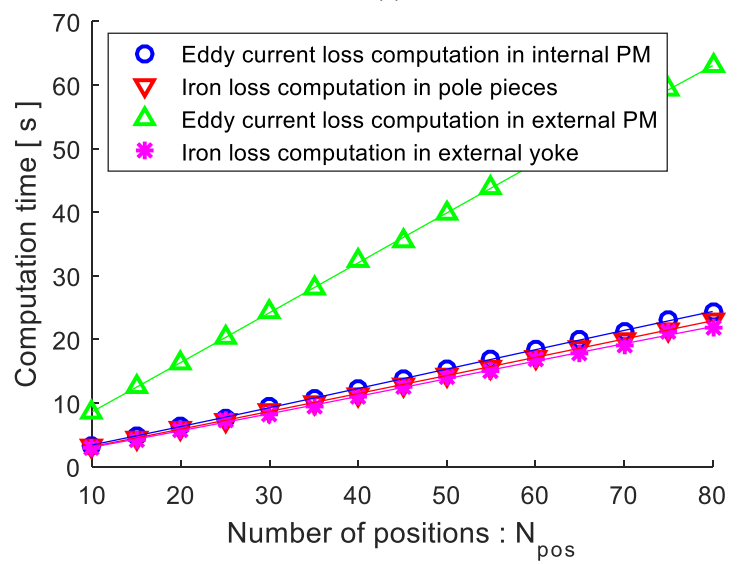

(b)

Fig. 13: Magnetic loss evaluation for various numbers of positions taken into account $\left(N_{\text {pos }}\right)$ for the magnetic gear described in Table II: a) precision, and b) computation time

To reduce computation time even further, [17] also suggested considering a small number of harmonics. In fact, with the values offered in [17] (i.e. $N_{Q}=5$ and $N / p_{\text {ext }}=3$ ), the computation time is once again lowered, with an error of less than $2 \%$ for both the iron loss computation and eddy current losses in permanent magnets of the internal ring computation. For the computation of eddy current losses in permanent magnets of the external ring, a higher number of harmonics must be considered $\left(N_{Q}=5=N / p_{\text {ext }}=7\right.$ are suggested herein). These values offer the possibility of cutting computation time by a factor of 100 (i.e. 30 min vs. 48 h).

\section{Analysis of the step-by-step process}

A compromise between computation time and precision must be found by modifying $N_{\text {pos }}$, i.e. the number of positions taken into account for the various magnetic loss computations. To evaluate the level of precision, the magnetic loss value references $P_{r e f}^{(k)}$ have been computed without any harmonics selection and with: $N_{\text {pos }}=150$, and $N_{Q}=N / p_{\text {ext }}=10$. It is then possible to analyze the computation time and precision of all magnetic loss evaluations, as indicated in Fig. 13, with the corresponding error defined in (24).

$$
\operatorname{Error}^{(k)}=\left|\frac{P_{\text {ref }}^{(k)}-P_{\text {Eddy/iron }}^{(k)}\left(\widehat{\theta_{\text {ext }}^{(k)}}, N_{\text {pos }}\right)}{P_{\text {ref }}^{(k)}}\right|
$$

TABLE III:

FIXED DIMENSIONS OF THE OPTIMIZATION

\begin{tabular}{clc}
\hline \hline \multirow{2}{*}{ Symbol } & \multicolumn{1}{c}{ Quantity } & Value \\
& & \\
\hline$P_{\text {rated }}$ & Wind turbine rated power & $6 \mathrm{MW}$ \\
$N_{\text {rated }}$ & Wind turbine rated speed & $12.5 \mathrm{rpm}$ \\
$T_{\text {rated }}$ & Wind turbine rated torque & $4.6 \mathrm{MNm}$ \\
$T_{G}$ & Maximum gear torque & $5.1 \mathrm{MNm}$ \\
$D$ & External diameter & $5.5 \mathrm{~m}$ \\
$l_{P M \text { min }}$ & Minimal splitting magnets width & $10 \mathrm{~mm}$ \\
$\delta_{\text {int }}$ & Internal air gap & $5 \mathrm{~mm}$ \\
$\delta_{\text {ext }}$ & External air gap & $5 \mathrm{~mm}$ \\
\hline \hline
\end{tabular}

Fig. 13 reveals that precision increases as a function of computation time. It is observed that the error remains below $10 \%$ with $N_{\text {pos }}=40$ for the eddy current loss computation in the external and internal rings, with $N_{\text {pos }}=10$ for the iron loss computation in the external yoke, and with $N_{\text {pos }}=50$ for the iron loss computation in pole pieces. These values will thus be assumed for the following sections of the present study, thus providing the possibility to further lower computation time by a factor of 30 (1 min vs. $30 \mathrm{~min})$.

\section{OPTIMIZATION EXAMPLE}

\section{A. Objective functions}

To illustrate the benefit of this hybrid analytical model, which serves to compute magnetic losses, a preliminary biobjective, mass-efficiency optimization protocol is proposed for a 6-MW and 12.5-rpm magnetic gear in a wind turbine application. This optimization routine has been introduced for various gear ratios. The objective functions (25) are twofold: to minimize the magnetic losses (objective function $C_{1}$ ), and to minimize the mass of the active magnetic gear parts (objective function $C_{2}$ ). The mass of the active parts takes into account the masses of: yokes $M_{\text {yokes }}$, permanent magnets $M_{P M}$, and pole pieces $M_{\text {pole pieces }}$.

$$
\left\{\begin{array}{c}
C_{1}=P_{E d d y}^{(I)}+Q \cdot P_{I r o n}^{(I I I, 1)}+P_{E d d y}^{(V)}+P_{\text {Iron }}^{(V I)} \\
C_{2}=M_{\text {yokes }}+M_{P M}+M_{\text {pole pieces }}
\end{array}\right.
$$

\section{B. Variables}

This optimization step is composed of six variables, namely: yoke thicknesses, permanent magnet thicknesses, pole piece thickness, and internal ring pole pairs $p_{\text {int }}$. For a gear ratio value $G_{m}$, the external ring pole pairs $p_{\text {ext }}$ is given in (26) so as to minimize the cogging torque [6], with the number of ferromagnetic pole pieces $Q$ determined by (1).

$$
p_{\text {ext }}=p_{\text {int }} \cdot\left|G_{m}\right|+1
$$

\section{Constrained dimensions}

Due to the 6-MW and 12.5-rpm wind turbine dimensions as well as a number of technological constraints, the different dimensions have been listed in Table III along with the oversizing proposed in [26]. The material properties are the same as those in Table I for the laminated steel grade M100065 and $\mathrm{NdFeB}$ permanent magnets. 


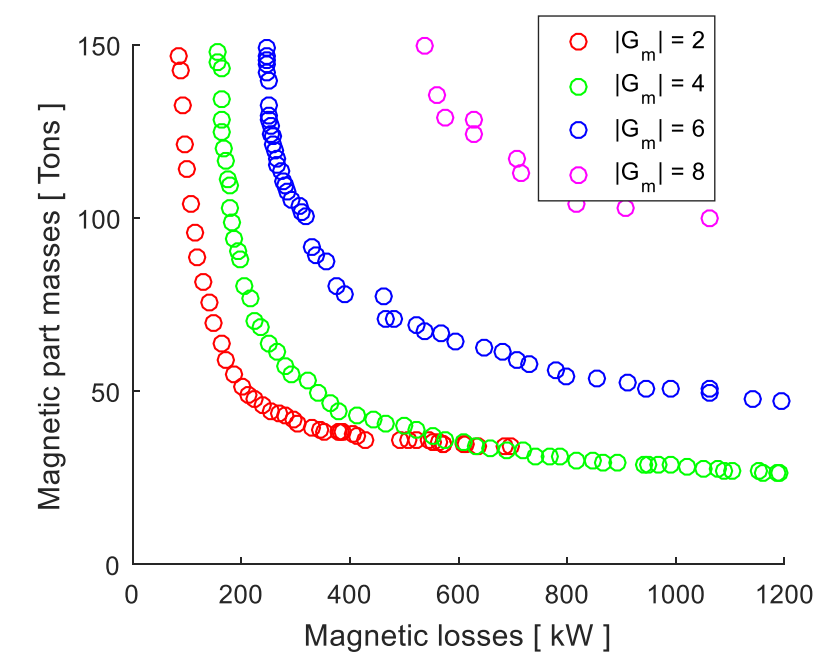

Fig. 14: Pareto front of the PSO bi-objective optimization protocol for various gear ratios of the 6-MW magnetic gear

\section{Optimization constraints}

Due to the linear magnetic behavior of the materials in the analytical model, a maximum induction value is tolerated in the ferromagnetic parts, as indicated in (27). On the other hand, a multibody mechanical analytical model of pole piece rings serves to evaluate the radial displacement $\mathcal{U}_{r}^{(I I I, q)}$ and normal stress $\sigma_{n}^{(I I I, q)}$ of the various $q$ pole piece support bars $(1<q<$ $Q)$. These bars are made of a non-magnetic material and constitute a cage, thus making it possible to ensure the mechanical maintenance of pole pieces [27]. The yield of this material is: $\sigma_{y}=400 \mathrm{MPa}$. It can then be imposed that the radial displacement must be less than $10 \%$ of the internal airgap (28) and the normal stress in the bars must be less than the yield stress $\sigma_{y}$ with a safety coefficient (29) [3]-[28].

$$
\begin{gathered}
\left\|B^{(k)}(r, \alpha, t)\right\|<B_{\max }=1.5 T \\
\mathcal{U}_{r}^{(I I I, q)}(r, \alpha, t)<0.1 * \delta_{\text {int }} \\
\sigma_{n}^{(I I I, q)}(r, \alpha, t)<2 / 3 * \sigma_{y}
\end{gathered}
$$

\section{E. Optimization procedure and results}

For a couple of parameters, this classical optimization procedure evaluates both objectives along with the various constraints. To complete this optimization step, a Particle Swarm Optimization (PSO) algorithm has been employed, as described in [29]. Optimization is performed in approximately $24 \mathrm{~h}$ for the different gear ratios with 100 particles and in 50 iterations (with an Intel Xeon E5-1630 v3, 8 threads, 3.70 $\mathrm{GHz}$ ).

Fig. 14 shows the Pareto front of the bi-objective PSO optimization with the objective function in (25) for different gear ratios. This result demonstrates that magnetic losses increase with gear ratio and may reach unacceptable values for a high-power energy conversion application (i.e. an efficiency below 90\%). It then becomes very important to integrate a magnetic loss evaluation based on analytical models within a magnetic gear optimization procedure. In contrast, minimizing losses by decreasing the gear ratio is of no interest since this would not reduce the input torque of the generator nor therefore its mass and cost. A compromise must be found, and this will take the form of a gear ratio optimization by considering the magnetic gear and the generator together.

\section{CONCLUSION}

This article has focused on a fast analytical model for magnetic loss computations in coaxial magnetic gear structures. The model derived takes into account the splitting of magnets (for eddy current losses) and spatial variations of the flux density (for losses in laminated ferromagnetic parts). The proposed 2D linear magnetostatic model is based on a hybrid analytical model that also serves to compute other magnetic gear parameters like torque, and radial and tangential loads [30].

The model for eddy current losses in permanent magnets proposed in this article has assumed a negligible magnetic reaction of the eddy current on the magnetic field distribution of permanent magnets. The results on a simplified eddy current loss model have been compared to results obtained with a magnetodynamic finite element model in an intermediate step (Fig. 6). This comparison has highlighted the validity limit of the magnetostatic analytical model (see Eq. 16). The iron loss model takes into account both the temporal and spatial variations of flux density. Fig. 9 has exposed the benefit of considering spatial variations.

A computation time analysis was also carried out, revealing the possibility of computing magnetic losses in approximately 1 min with an error of less than $10 \%$ for a $3.9-\mathrm{MW}, 15-\mathrm{rpm}$ magnetic gear [3] (with an Intel Xeon E5-1630 v3, 8 threads, 3.70 GHz).

The final function of this analytical model must be integrated into a set of models for the global mechatronic optimization of magnetic gears. A preliminary bi-objective mass-efficiency optimization protocol with various constraints was then proposed to illustrate the feasibility of such a mechatronic optimization due to the low computation time generated by this hybrid analytical model (Fig. 14). Results have also illustrated the need to take losses into account for magnetic gear optimization given their strong impact on magnetic gear dimensions.

In subsequent work, a mechanical analytical model of the structural parts of the magnetic gear must be proposed in order to complete global mechatronic optimization. The 3D effects of the magnetic loss computations must still be evaluated.

\section{REFERENCES}

R. Lacal Arántegui and J. Serrano Gonzáles, "Wind status report: Technology, market and economic aspects of wind energy in Europe," JRC, 2015.

[2] J. Keller, Y. Guo, and L. Sethuraman, "Gearbox Reliability Collaborative Investigation of Gearbox Motion and High-SpeedShaft Loads," NREL, Tech. Rep. TP-5000-65321, 2016.

[3] M. Desvaux, R. Le Goff Latimier, B. Multon, H. Ben Ahmed, and S. Sire, "Design and optimization of magnetic gears with arrangement and mechanical constraints for wind turbine applications," in 11th International Conference EVER, 2016.

[4] T. B. Martin, "Magnetic transmission," Pat. US3378710, 1968. 
[5] K. Atallah and D. Howe, "A novel high-performance magnetic gear," IEEE Trans. Magn., vol. 37, no. 4, pp. 2844-2846, 2001.

[6] K. Atallah, S. D. Calverley, and D. Howe, "Design, analysis and realisation of a high-performance magnetic gear," IEE Proc - Electr. Power Appl., vol. 151, no. 2, pp. 135-143, 2004.

[7] P. O. Rasmussen \& al., "Development of a high-performance magnetic gear," IEEE Trans. Ind. Appl., vol. 41, no. 3, pp. 764-770, 2005.

[8] N. W. Frank \& al., "Passive Suppression of Transient Oscillations in the Concentric Planetary Magnetic Gear," IEEE Trans. Energy Convers., vol. 26, no. 3, pp. 933-939, 2011.

[9] L. Jian, K. T. Chau, and S. Member, "A Coaxial Magnetic Gear With Halbach Permanent-Magnet Arrays," IEEE Trans. Energy Convers., vol. 25, no. 2, pp. 319-328, 2010.

[10] S. Kim \& al., "Optimal Design of Novel Pole Piece for Power Density Improvement of Magnetic Gear Using Polynomial Regression Analysis," IEEE Trans. Energy Convers., pp. 1-9, 2015.

[11] J. Shen, H. Li, H. Hao, and M. Jin, "A Coaxial Magnetic Gear with Consequent-Pole Rotors," IEEE Trans. Energy Convers., vol. 8969, no. c, pp. 1-9, 2016

[12] E. Gouda, S. Mezani, L. Baghli, and A. Rezzoug, "Comparative study between mechanical and magnetic planetary gears," IEEE Trans. Magn., vol. 47, no. 2, pp. 439-450, 2011.

[13] A. Penzkofer and K. Atallah, "Magnetic Gears for High Torque Applications," IEEE Trans. Magn., vol. 50, no. 11, 2014.

[14] P. O. Rasmussen \& al., "Experimental Evaluation of a Motor Integrated Permanent Magnet Gear," in IEEE Energy Conversion Congress and Exposition (ECCE 2011), 2011, pp. 3982-3989.

[15] M. Desvaux, B. Multon, S. Sire, and H. Ben Ahmed, "Analytical Iron Loss Model for the Optimization of Magnetic Gear," IEEE Int. Electr. Mach. Drives Conf. 2017, IEMDC2017, 2017.

[16] T. Lubin, S. Mezani, and A. Rezzoug, "Analytical computation of the magnetic field distribution in a magnetic gear," IEEE Trans. Magn., vol. 46, no. 7, pp. 2611-2621, 2010.

[17] M. Desvaux, B. Traullé, R. L. G. Latimier, S. Sire, B. Multon, and H. Ben Ahmed, "Computation Time Analysis of the Magnetic Gear Analytical Model," IEEE Trans. Magn., vol. 53, no. 5, 2017.

[18] V. Ostović, "Dynamics of Saturated Electric Machines," in New York Springer-Verlag, 1989.

[19] O. de la Barriere \& al., "An analytical model for the computation of no-load eddy current losses in the rotor of a permanent magnet synchronous machine," IEEE Trans. Magn., vol. 2, pp. 1-1, 2013.

[20] C. A. Hernandez-Aramburo, T. C. Green, and A. C. Smith, "Estimating Rotational Iron Losses in an Induction Machine," IEEE Trans. Magn., vol. 39, no. 6, pp. 3527-3533, 2003.

[21] S. Ouagued, a. A. Diriyé, Y. Amara, and G. Barakat, "A General Framework Based on a New Hybrid Analytical Model for the Analysis and Design of Permanent Magnet Machines," IEEE Trans. Magn., vol. 58, no. 5, p. 2149, 2014.

[22] Kais Atallah, David Howe, Philip H. Mellor, "Rotor eddy-current loss in permanent-magnet brushless AC machines," IEEE Trans. Magn., vol. 46, no. 7, pp. 2701-2707, 2010.

[23] G. Bertotti \& al., "An improved estimation of iron losses in rotatinf electrical machines," IEEE Trans. Magn., vol. 27, no. 6, pp. 50075009, 1991.

[24] F. Deng, "An improved iron loss estimation for permanent magnet brushless machines," IEEE Trans. Energy Convers., vol. 14, no. 4, pp. 1391-1395, 1999.

[25] M. Fratila, A. Benabou, A. Tounzi, and M. Dessoude, "Calculation of Iron Losses in Solid Rotor Induction Machine Using FEM," IEEE Trans. Magn., vol. 50, no. 2, pp. 2-5, 2014.

[26] M. Desvaux, R. Le Goff Latimier, B. Multon, S. Sire, and H. Ben Ahmed, "Analysis of the Dynamic Behaviour of Magnetic Gear with Nonlinear Modelling for Large Wind Turbines," in ICEM 2016, 2016, pp. 1332-1338.

[27] M. Desvaux, B. Multon, H. Ben Ahmed, and S. Sire, "Supporting the laminated ferromagnetic pole pieces in a magnetic gear: a structure behaviour analysis from a multibody model," in MuSMe 2017. Mech. and Machine Science, vol 54. Springer, 2017, pp. 85-94.

[28] A. Zavvos, A. S. Mcdonald, and M. Mueller, "Structural optimisation tools for iron cored permanent magnet generators for large direct drive wind turbines," in IET Conference RPG 2011, 2011.

[29] J. Aubry, H. Ben Ahmed, and B. Multon, "Sizing optimization methodology of a surface permanent magnet machine-converter system over a torque-speed operating profile: Application to a wave energy converter," IEEE Trans. Ind. Electron., vol. 59, no. 5, pp. 2116-2125, 2012.

[30] M. Filippini and P. Alotto, "Coaxial magnetic gears design and optimization," IEEE Trans. Ind. Electron., vol. 46, no. c, 2017.

\section{BIOGRAPHIES}

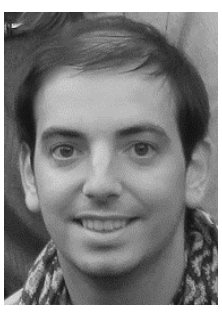

Melaine Desvaux received a joint B.S. degree in electronics and telecommunications and in mechanical engineering in 2012, followed by an M.S. degree in mechatronic design in 2015, from the University of Rennes 1 (France). He passed the "Agrégation" credentialing exam in Mechanical Engineering in 2014 and is currently pursuing a Ph.D. in Mechatronic Engineering at the SATIE Laboratory (ENS Rennes, France).

His research topics include the integration of magnetic gears in wind power applications, a field that requires skills in mechanical engineering, optimization and.magnetism.

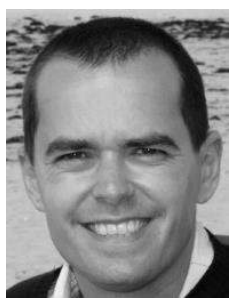

Stéphane Sire received his Ph.D. in mechanical engineering in 2002 from the Ecole Centrale Nantes (France). Since 2005, he has held the post of Assistant Professor at the University of Brest (France). He was awarded an accreditation to supervise research (HDR) in 2016.

Stéphane's research topics include the mechanical behavior of materials, assemblies and structures (experimental characterization and modeling).

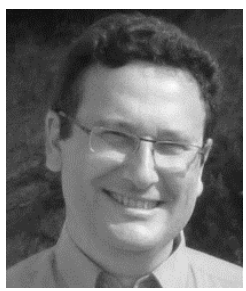

Bernard Multon received his M.S. degree in electrical engineering from the Ecole Normale Supérieure de Cachan (France) in 1981, followed by an "Agrégation" credential in Electrical Engineering in 1982 and then a Ph.D. from the University of Paris 6 in 1985. From 1988 to 1995 , Bernard was an Assistant Professor in the Electrical Engineering Department, at ENS Cachan, and Leader of the Research-based Special Actuator Design Group at LESiR-CNRS. Since 1995, he has held the post of Full Professor at ENS Rennes teaching in the Mechatronics Department. His research is conducted with the SETE team of the SATIE-CNRS Laboratory and focuses on the sizing of electromechanical chains and the management of renewable electrical energy conversion systems throughout their life cycle.

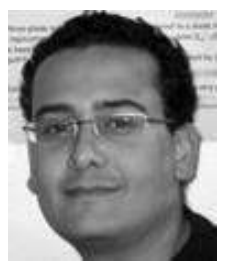

Sami Hlioui received an M.Sc. degree in electrical engineering from the Ecole Normale Supérieure (ENS) de Cachan, France and a Ph.D. in electrical power engineering from the University of Technology of BelfortMontbéliard (UTBM), France in 2008. Since 2010, he has held the post of Assistant Professor at CNAM-Paris.

His research interests include the multidisciplinary design of electrical machines.

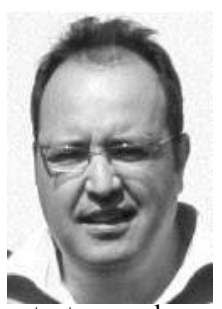

Hamid Ben Ahmed received his Ph.D. and HDR accreditation to supervise research in 1994 and 2006, respectively. From 1994 to 1997, he worked as a Research Associate in the SATIE Laboratory. Since 1997, Hamid has held the post of Assistant Professor in the Mechatronics Department at ENS Cachan (France), through the institution's transition to become ENS Rennes.

His research interests include the design, modeling and optimization of novel topologies for electromagnetic actuators and generators, as well as the optimization of renewable energy systems. 